\title{
Urbanización y clases sociales. La experiencia de la desigualdad en la estructuración del área metropolitana de Asunción
}

\section{Urbanization and social classes. The experience of inequality in the organization of the metropolitan area of Asunción}

\author{
Georgina Zavattiero Tornatore ${ }^{1}$ y Luis Alberto Ortiz Sandoval ${ }^{2}$
}

Fecha de recepción: 04-03-2019 — Fecha de aceptación: 04-07-2019

Hábitat y Sociedad (ISSN 2173-125X), n. ${ }^{\circ}$ 12, noviembre de 2019, pp. 91-111.

http://dx.doi.org/10.12795/HabitatySociedad.2019.i12.06

\begin{abstract}
The Metropolitan Area of Asunción (AMA) has experienced an accelerated and disorganized process of urbanization due to the establishment of a normative and institutional framework that facilitates the market and deregulates territorial planning, promoting domineering social actors to impose their interests and to profit from their revenues, socializing the negative impacts that they cause. The main objective of this work is therefore to expose the characteristics of the connection between the social structure and the urban experience of the inhabitants of the metropolitan area of Asuncion. The methodology is predominantly qualitative, since the reflections of the inhabitants of the AMA are taken up, according to their position in the Paraguayan social structure, regarding the subjective representations about the daily experience of urban residence. Additionally, official statistics of indicators related to the object of study are analyzed. The main findings confirm the contradictions that arise within the urbanization process of the AMA, in which the antagonisms that emerge in a society that aims to strengthen the urban development from the market are revealed, demonstrating that the position of the inhabitants in the social structure has a direct impact on the possibilities of satisfying their demands as well as the usufruct of the city potentialities.
\end{abstract}

\section{Key words}

Social inequality; Social stratification; Habitats; Urbanization; Housing

\section{Resumen}

El área metropolitana de Asunción (AMA) ha experimentado un acelerado y desorganizado proceso de urbanización, debido a la instauración de un marco institucional y normativo facilitador del mercado y desregulador del planeamiento territorial, propiciando que actores sociales dominantes consigan imponer sus intereses, y usufructuar sus réditos, socializando los impactos negativos que estos provocan. El objetivo principal de este estudio es, por lo tanto, exponer las características de la relación entre la estructura social y la experiencia urbana de los habitantes del área metropolitana asuncena. La metodología utilizada es predominantemente cualitativa, en tanto se retoman las reflexiones de los habitantes del AMA, según su posicionamiento en la estructura social paraguaya, respecto a las representaciones subjetivas sobre la experiencia cotidiana de la residencia urbana. De manera complementaria, se analizan estadísticas oficiales de indicadores relativos al objeto de estudio. Los principales hallazgos permiten constatar las contradicciones que se gestan en el seno del proceso de urbanización del AMA, en el cual se revelan los antagonismos que emergen en una sociedad que pretende apuntalar el desarrollo urbano desde el mercado, dando cuenta de que el posicionamiento de los habitantes en la estructuración social posee directa incidencia en las posibilidades de satisfacción de sus demandas como del usufructo de las potencialidades citadinas.

\section{Pallabras clave}

Desigualdad social; Estratificación social; Hábitat; Urbanización; Vivienda

1 Licenciada en Trabajo Social por la Universidad Nacional de Asunción, Paraguay. Mgtr. en Ciencias Sociales con mención en Desarrollo Social por la Facultad Latinoamericana de Ciencias Sociales (FLACSO), Paraguay. E-mail: georgina.zavattiero.t@gmail.com 2 Licenciado en Sociología. Mgter. en Ciencias Sociales por la Facultad Latinoamericana de Ciencias Sociales (FLACSO), México. Doctor en Sociología por la Escuela de Altos Estudios en Ciencias Sociales, Francia. Actualmente está realizando estancia posdoctoral en The New School University, Estados Unidos. E-mail: 1.ortizs@yahoo.com 


\section{Introducción}

La organización socio-espacial y económica del territorio metropolitano de Asunción es una expresión de las desigualdades sistémicas y de los desequilibrios estructurales que afectan al Paraguay (Causarano, 2006), producto de un modelo económico vinculado a la expansión de la frontera agroindustrial, con marcada concentración de tierra y escasa absorción de mano de obra (Esquivel Vaesken, 2007).

Dicho modelo, que se consolida en las últimas décadas del siglo xx, se convierte en el factor principal de expulsión de personas del campo a la ciudad, es decir, de la migración interna, que aporta de manera significativa al crecimiento urbano (Morínigo, 1998; Borda, 2016; Ortiz, Goetz y Gache, 2017). La modificación en los patrones de tenencia de la tierra y de la producción agrícola convergen en impulsar la retracción de la agricultura campesina y la exhortación de buscar nuevos lugares de residencia para la población rural sobrante (Imas, 2013).

En este sentido, desde la década de 1990 se experimenta con mayor énfasis el desplazamiento de habitantes rurales empobrecidos hacia los focos de las ciudades más urbanizadas, fenómeno que incidió de manera decisiva en el acelerado y desorganizado ritmo de urbanización del país (Zavattiero, 2016). Dicho suceso advierte que la urbanización no responde a un proceso deliberado de planificación pública que permitiese saldar la compleja lógica de exclusión social, sino que se suscitó como una consecuencia que agravó la situación de pauperización y precariedad de los amplios sectores que progresivamente se incorporaron a la matriz urbana (Morínigo, 1998).

Cabe señalar que la escasa planificación, previsión y capacidad en la gestión territorial por parte de las instituciones públicas, restringen severamente la organización eficaz del territorio (Vázquez, 2013) y, además de generar graves perjuicios ambientales y económicos, atentan contra el desarrollo equitativo de la sociedad urbana paraguaya.

Dicha coyuntura, asociada además a la complaciente venia del aparato estatal para con los intereses económicos hegemónicos, habilitó la oportunidad para que el mercado se nutra de las posibilidades que surgen de estos territorios, apuntalando el ordenamiento territorial urbano según un criterio de rentabilidad y no de interés público, afectando de manera sustancial la eficiencia funcional metropolitana y provocando la reproducción desmedida de las desigualdades e inequidades de recursos y habitantes.

Al respecto, y pese al proceso tardío pero acelerado de urbanización que experimentó el país en comparación al resto de la región, no se ha visto exento de padecer el deterioro de las condiciones de vida urbana y el agravamiento de las desigualdades socio-espaciales propias de las ciudades de América Latina que han dado cabida a un modelo de gobernanza direccionado por los intereses y necesidades del sector empresarial.

En consecuencia, entendiendo que en la construcción de las ciudades están presentes relaciones de poder con base en la estructuración social, las mismas están detrás de los modelos de producción del territorio y de la convivencia social, de modo que los interrogantes que orientan este estudio son: ¿Cómo se vinculan los habitantes de las diferentes clases sociales con las transformaciones socio-espaciales de las ciudades del área metropolitana de Asunción? ¿De qué manera las desigualdades sociales se manifiestan en los modos de residencia y relacionamiento entre los habitantes de la misma? 
En este marco, el objetivo general del estudio es exponer las características de la relación entre la estructura social y la experiencia urbana de los habitantes del área metropolitana asuncena. Los objetivos específicos del mismo son, por un lado, establecer las representaciones sociales de los habitantes de las diferentes clases sociales y las transformaciones socioespaciales que operan en el territorio metropolitano de Asunción, y, por otro lado, describir las implicancias de las desigualdades en los patrones de habitabilidad y en las relaciones sociales entre los mismos grupos que habitan dicho territorio urbano.

Para el efecto, la propuesta metodológica se planteó a partir de un abordaje cualitativo desde el cual se efectuó la aplicación y análisis de entrevistas en profundidad a habitantes urbanos, según clases sociales, residentes en el AMA. Complementariamente, se utilizaron estadísticas descriptivas de datos oficiales del país que posibilitaron evidenciar las desigualdades tanto en la provisión de servicios básicos como en la situación legal y de acceso a la vivienda. El período de estudio de esta investigación se encuadra entre los años 2002 y 2017.

\section{Marco teórico}

El proceso de urbanización es un conjunto de transformaciones que lleva a centrar la organización del territorio en la ciudad, convirtiéndose en el espacio donde convergen los cambios económicos productivos, la concentración del capital, la innovación tecnológica, la atracción de las migraciones por desposesión y las nuevas dinámicas sociales, entre las que se hallan la densificación de los flujos y las interacciones humanas. En este sentido, Wirth señala que la urbanización no se ciñe meramente a una aglomeración de personas en un territorio, sino que la misma refiere también a "esa acentuación acumulativa de las características distintivas del modo de vida que está asociado al crecimiento de las ciudades, y finalmente, los cambios en la dirección de los modos de vida reconocidos como urbanos y manifiestos en la gente" (1962, p. 3).

En la actualidad, las ciudades son escenarios de una diversa gama de desigualdades que afectan de modo directo a la apropiación y al usufructo equitativo de los servicios y oportunidades que de los mismos emergen. La expansión y acentuación de las políticas urbanas neoliberales refuerzan el rezago en el cumplimiento de los compromisos sociales con los habitantes, específicamente la vivienda y empleo, así como se priorizan los intereses requeridos por el mercado y la consecuente obtención de réditos económicos. En este sentido, las ciudades han experimentado un agravamiento en torno a las desigualdades y la segregación urbana asociados a un complaciente aparato estatal aliado con los intereses corporativistas (Díaz Orueta y Lourés Seoane, 2013).

En este aspecto, Antón entiende que la "desigualdad social es un concepto relacional o comparativo. Significa la existencia de distintas oportunidades en el acceso, posesión, control y disfrute de recursos y poder, derivadas de diferentes condiciones, contextos y trayectorias" (2013, p. 2). Este autor señala que existe un consenso ético básico en el cual algunos tratos desiguales son considerados "ilegítimos", mientras que otros, como los ocasionados por el sistema económico, son más "discutibles" aunque no por eso menos condenables, y en virtud de ello considera que la manifestación del amplio rechazo ciudadano expresa el intento de deslegitimar la desigualdad social y de los actores que las entrañan (Antón, 2013). 
Asimismo, la estructuración social posee una evidente incidencia en las desigualdades que experimentan los habitantes en su cotidianidad. En cuanto al caso paraguayo, desde los inicios de la nación la estructura social del país se ha caracterizado por una acentuada polarización de clases (Rivarola, 2016). De acuerdo con esto, Luis Ortiz señala que:

La desigualdad social se configura con sectores sociales intermedios en la estructura social y delinea una estructuración tripartita pero polarizada de clases: las clases superiores y clases medias, de baja representación demográfica, concentran los recursos de propiedad y calificación, así como comparten una experiencia social (estilos de vida) que clausura su apertura a las clases subordinadas, estas últimas vetadas del acceso a la propiedad y con bajos niveles de calificación, aún si constituyen el sector demográficamente mayoritario de la población (2016, p. 280).

Ortiz sostiene que la sociedad paraguaya se caracteriza por una estructuración tripartita constituida por la clase desfavorecida, la clase media y la clase dominante, que se determina, principalmente por la correspondencia entre los niveles de ingresos y los años de estudios, dando cuenta de que "las diferencias de volúmenes de uno y otro respectivamente operan como mecanismos de separación entre las clases sociales, generando distancias sociales no solo en términos socioeconómicos, sino también en términos de las condiciones de existencia y de estilos de vida entre unas clases y otras, constituyendo esas distancias el principio explicativo de la diferenciación jerárquica de los grupos en la sociedad" (ob. cit., p. 288).

La estratificación social tiene su notoria expresión en la exclusión de personas del entramado social y en la negación de sus derechos. Exclusión que adquiere un carácter multidimensional y dinámico al restringir el normal desenvolvimiento y participación de algunos grupos sociales, posicionándolos en condición de desventaja frente a otros. Al respecto, Prebisch propone un análisis de la exclusión social señalando que:

Aquella distribución tan inequitativa de los frutos del desarrollo se debe primordialmente a la apropiación por los estratos superiores de la estructura social de una parte considerable del fruto del progreso técnico en forma de excedente económico [...] el sistema tiende así a excluir grandes masas que quedan vegetando en el fondo de la estructura social (1981, p. 15).

Tal como expresan Bourdieu y Wacquant, "existe una correspondencia entre las estructuras sociales y las estructuras mentales, entre las divisiones objetivas del mundo social - particularmente en dominantes y dominados en los diversos campos- y los principios de visión y división que los agentes aplican" (2008, p. 36); por tanto, y asumiendo que la estructuración social permea el registro de los individuos y la configuración de sus experiencias sociales, es que se puede señalar que los mismos construyen representaciones que les permiten dar sentidos a sus conductas y reflexionar sobre la realidad circundante. Tales representaciones, en palabras de Durkheim, lo que expresan es "la manera en que el grupo se piensa en sus relaciones con los objetos que lo afectan [...]. Las representaciones, las emociones, las tendencias colectivas no tienen por causas generadoras ciertos estados de las conciencias particulares, sino las condiciones en 
que se encuentra el cuerpo social en su conjunto" (2001, p. 23-159). Por su parte, dando cuenta del carácter social de las representaciones, es que Moscovici expresa que:

La representación social es un corpus organizado de conocimientos y una de las actividades psíquicas gracias a las cuales los hombres hacen inteligible la realidad física y social, se integran en un grupo o en una relación cotidiana de intercambios, liberan los poderes de su imaginación" [...] una representación social condensa una reflexión colectiva bastante directa, diversificada y difusa, en la que cada uno de los participantes es, hasta cierto punto, un autodidacto y, como todo autodidacto, su ideal es, al mismo tiempo, el diccionario y la enciclopedia (1979, p. 18-53)

La estructuración social y su correlato en las representaciones sociales delinean los usos y apropiaciones legitimados para el territorio urbano según clases sociales. En las ciudades capitalistas y neoliberales, la significancia de la expansión y acumulación económica tiene su alcance territorial y se verifica en la expulsión rutinaria de los habitantes de bajos recursos económicos de sus territorios de residencia. Este fenómeno, producto de los esfuerzos generados por el ensamblaje económico y político, identifica los espacios territoriales ganados como recursos para la extracción de rentabilidad y atracción de inversiones, ocasionando así la reconfiguración de las relaciones de clase en las ciudades (Janoscka, 2016).

Adicionalmente, la asimilación de estos procesos territoriales, de la jerarquización social, y las profundas raíces históricas de las que emanan las brechas de desigualdades y exclusión social, conforman un ramaje de dificultades que afectan a los seres humanos en sus interacciones socio-espaciales y en sus contextos residenciales, es decir, en sus hábitats. $\mathrm{Al}$ respecto, Enrique Leff afirma que hábitat es:

Espacio donde se desarrollan las actividades productivas, culturales, estéticas y afectivas del hombre. Es el medio donde los seres vivos evolucionan y complejizan su existir, donde el organismo social despliega sus potencialidades, es espacio donde define su territorialidad [...]. El hábitat es soporte y condición, al tiempo que es espacio resignificado y reconstruido por la cultura (1998, citado en ONU-Hábitat, 2004, p. 36).

$\mathrm{Al}$ referir la noción de hábitat, como constructo humano para la reproducción de la vida, resulta ineludible señalar la categoría de vivienda como elemento compositivo fundamental. En relación a esto, Castillo expresa que la vivienda es una institución social que cuenta con la característica de poseer valor de uso y valor de cambio, en vista a que:

Hace posible la construcción de un sentido de pertenencia a un lugar, de una cierta sensación de bienestar, el sitio de las realizaciones individuales y familiares (dimensión sociocultural), soporte material para la reproducción familiar y como fuerza de trabajo o referente de un status social (dimensión socioeconómica), todo esto concerniente a la casa como entorno inmediato, pero también en sus relaciones que la convierten en hábitat y la conectan con un entorno más amplio [...] algunos adicionales, como son el valor del suelo urbano y de los materiales utilizados en la construcción, determinan un valor de cambio que convierten a la vivienda en una mercancía, objeto de intercambio en diversos tipos de mercados o submercados e instrumento de especulación financiera (2004, p. 16). 
En el marco de estos análisis, entenderemos que el resultado de la urbanización acelerada en Paraguay adopta la forma de expansión metropolitana "metropolización", en torno a la ciudad de Asunción y, para el efecto, asumimos la categoría conceptual formulada por Causarano en la cual enfatiza que "la metropolización es el proceso por el cual una ciudad principal, la metrópolis, y otras colindantes conforman un continuum urbanizado, que adquiere las características de una urbe extendida" (2006, p. 23).

\section{Materiales y métodos}

El trabajo moviliza cinco categorías teóricas (ver Cuadro 1) con un planteo metodológico que posibilita su correspondencia empírica. Esto se lleva a cabo desde un abordaje preponderantemente cualitativo, basado en entrevistas en profundidad, realizadas en el año 2017, a habitantes del AMA según clases sociales y a expertos de diferentes disciplinas de las ciencias sociales. Complementariamente, se recurre a información estadística de datos oficiales del país que posibilitan evidenciar las asimetrías tanto en la provisión de servicios básicos como en la situación legal y de acceso a la vivienda.

\begin{tabular}{|c|c|c|c|c|}
\hline Categorías & $\begin{array}{l}\text { Dimensiones de } \\
\text { análisis }\end{array}$ & $\begin{array}{l}\text { Unidades de } \\
\text { observación }\end{array}$ & Técnicas & Instrumentos \\
\hline \multirow{2}{*}{$\begin{array}{l}\text { Proceso de } \\
\text { urbanización }\end{array}$} & $\begin{array}{l}\text { Representación de los } \\
\text { cambios urbanos en el } \\
\text { AMA }\end{array}$ & $\begin{array}{l}\text { Habitantes de clases } \\
\text { desfavorecida, media y } \\
\text { superior }\end{array}$ & $\begin{array}{l}\text { Entrevistas en profun- } \\
\text { didad }\end{array}$ & $\begin{array}{l}\text { Guía de entrevista se- } \\
\text { mi-estructurada }\end{array}$ \\
\hline & $\begin{array}{l}\text { Migración interurbana } \\
\text { de los habitantes }\end{array}$ & $\begin{array}{l}\text { Migrantes interurba- } \\
\text { nos }\end{array}$ & $\begin{array}{l}\text { Entrevistas en profun- } \\
\text { didad }\end{array}$ & $\begin{array}{l}\text { Guía de entrevista se- } \\
\text { mi-estructurada }\end{array}$ \\
\hline \multirow{2}{*}{ Clase social } & $\begin{array}{l}\text { Categoría socio-ocupa- } \\
\text { cional }\end{array}$ & $\begin{array}{l}\text { Habitantes de clases } \\
\text { desfavorecida, media y } \\
\text { superior }\end{array}$ & $\begin{array}{l}\text { Entrevistas en profun- } \\
\text { didad }\end{array}$ & $\begin{array}{l}\text { Guía de entrevista se- } \\
\text { mi-estructurada }\end{array}$ \\
\hline & $\begin{array}{l}\text { Experiencia subjetiva } \\
\text { de clase }\end{array}$ & $\begin{array}{l}\text { Habitantes de clases } \\
\text { desfavorecida, media y } \\
\text { superior }\end{array}$ & $\begin{array}{l}\text { Entrevistas en profun- } \\
\text { didad }\end{array}$ & $\begin{array}{l}\text { Guía de entrevista se- } \\
\text { mi-estructurada }\end{array}$ \\
\hline \multirow{2}{*}{$\begin{array}{l}\text { Hábitat } \\
\text { integral }\end{array}$} & $\begin{array}{l}\text { Distanciamiento de } \\
\text { factores ambientales } \\
\text { de riesgos }\end{array}$ & $\begin{array}{l}\text { Habitantes de clases } \\
\text { desfavorecida, media y } \\
\text { superior / Hogares }\end{array}$ & $\begin{array}{l}\text { Entrevistas en profun- } \\
\text { didad }\end{array}$ & $\begin{array}{l}\text { Guía de entrevista se- } \\
\text { mi-estructurada }\end{array}$ \\
\hline & $\begin{array}{l}\text { Representaciones ciu- } \\
\text { dadanas sobre la cali- } \\
\text { dad de vida en su ciu- } \\
\text { dad }\end{array}$ & $\begin{array}{l}\text { Habitantes de clases } \\
\text { desfavorecida, media y } \\
\text { superior }\end{array}$ & $\begin{array}{l}\text { Entrevistas en profun- } \\
\text { didad }\end{array}$ & $\begin{array}{l}\text { Guía de entrevista se- } \\
\text { mi-estructurada }\end{array}$ \\
\hline \multirow{3}{*}{$\begin{array}{l}\text { Exclusión } \\
\text { social }\end{array}$} & $\begin{array}{l}\text { Interpretación de las li- } \\
\text { mitaciones que genera } \\
\text { la pobreza en la parti- } \\
\text { cipación de la vida ciu- } \\
\text { dadana }\end{array}$ & $\begin{array}{l}\text { Habitantes de clase } \\
\text { desfavorecida }\end{array}$ & $\begin{array}{l}\text { Entrevistas en profun- } \\
\text { didad }\end{array}$ & $\begin{array}{l}\text { Guía de entrevista se- } \\
\text { mi-estructurada }\end{array}$ \\
\hline & $\begin{array}{l}\text { Participación ciudada- } \\
\text { na en materia de de- } \\
\text { sarrollo urbano de su } \\
\text { localidad }\end{array}$ & $\begin{array}{l}\text { Habitantes de clases } \\
\text { desfavorecida, media y } \\
\text { superior }\end{array}$ & $\begin{array}{l}\text { Entrevistas en profun- } \\
\text { didad }\end{array}$ & $\begin{array}{l}\text { Guía de entrevista se- } \\
\text { mi-estructurada }\end{array}$ \\
\hline & $\begin{array}{l}\text { Estigmatización territo- } \\
\text { rial experimentada }\end{array}$ & $\begin{array}{l}\text { Habitantes de clase } \\
\text { desfavorecida }\end{array}$ & $\begin{array}{l}\text { Entrevistas en profun- } \\
\text { didad }\end{array}$ & $\begin{array}{l}\text { Guía de entrevista se- } \\
\text { mi-estructurada }\end{array}$ \\
\hline
\end{tabular}




\begin{tabular}{|c|c|c|c|c|}
\hline Categorías & $\begin{array}{l}\text { Dimensiones de } \\
\text { análisis }\end{array}$ & $\begin{array}{l}\text { Unidades de } \\
\text { observación }\end{array}$ & Técnicas & Instrumentos \\
\hline & $\begin{array}{l}\text { Restricciones en la in- } \\
\text { tegración socio-terri- } \\
\text { torial }\end{array}$ & $\begin{array}{l}\text { Habitantes de clases } \\
\text { desfavorecida, media } \\
\text { y superior / Expertos } \\
\text { (sociólogos o afines) }\end{array}$ & $\begin{array}{l}\text { Entrevistas en profun- } \\
\text { didad }\end{array}$ & $\begin{array}{l}\text { Guía de entrevista se- } \\
\text { mi-estructurada }\end{array}$ \\
\hline \multirow{3}{*}{ Vivienda } & $\begin{array}{l}\text { Significaciones en tor- } \\
\text { no a la vivienda }\end{array}$ & $\begin{array}{l}\text { Habitantes de clases } \\
\text { desfavorecida, media y } \\
\text { superior }\end{array}$ & $\begin{array}{l}\text { Entrevistas en profun- } \\
\text { didad }\end{array}$ & $\begin{array}{l}\text { Guía de entrevista se- } \\
\text { mi-estructurada }\end{array}$ \\
\hline & $\begin{array}{l}\text { Mecanismos de acceso } \\
\text { a la vivienda urbana }\end{array}$ & $\begin{array}{l}\text { Habitantes de clases } \\
\text { desfavorecida, media y } \\
\text { superior / Hogares }\end{array}$ & $\begin{array}{l}\text { Entrevistas en profun- } \\
\text { didad / Estadísticas } \\
\text { descriptivas }\end{array}$ & $\begin{array}{l}\text { Guía de entrevista se- } \\
\text { mi-estructurada / En- } \\
\text { cuesta Permanente de } \\
\text { Hogares }\end{array}$ \\
\hline & $\begin{array}{l}\text { Constructos sociales } \\
\text { en torno a la habitabi- } \\
\text { lidad }\end{array}$ & $\begin{array}{l}\text { Habitantes de clases } \\
\text { desfavorecida, media y } \\
\text { superior }\end{array}$ & $\begin{array}{l}\text { Entrevistas en profun- } \\
\text { didad }\end{array}$ & $\begin{array}{l}\text { Guía de entrevista se- } \\
\text { mi-estructurada }\end{array}$ \\
\hline
\end{tabular}

Las ciudades del área metropolitana de Asunción consideradas en este trabajo son, además de Asunción, la capital paraguaya, aquellas que lindan con la misma, como son Fernando de la Mora, Lambaré, Luque y Mariano Roque Alonso. De igual manera, la ciudad de San Lorenzo, perteneciente a la zona metropolitana de Asunción, fue tenida en cuenta para el estudio por la preponderancia que presenta para la región del AMA.

En consecuencia, se realizaron 38 entrevistas en profundidad a habitantes urbanos, cuya selección fue por medio del método en cascada, con perspectiva de género y según la categorización de estructuración tripartita de la sociedad paraguaya, es decir, clase desfavorecida, media y superior. En las ciudades del área metropolitana se aplicaron 6 entrevistas en profundidad a habitantes residentes en cada distrito y seleccionando 2 jefes/as de hogares para cada clase social. Asimismo, en Asunción se realizaron 8 entrevistas en profundidad: a 4 jefes de hogares de clase desfavorecida, 2 jefes de hogares de clase media y 2 jefes de hogares de clase superior.

En lo que respecta a especialistas de diferentes disciplinas de las ciencias sociales, se recurrió a 6 profesionales (sociólogos, arquitectosurbanistas y geógrafos). En el empleo de la información estadística, se procedió a un análisis descriptivo con información de fuente secundaria proveniente de datos oficiales abarcando el periodo comprendido entre los años 2002 y 2016.

\section{Resultados y discusión}

\section{Desigualdad territorial en el área metropolitana de Asunción: restricciones para la integración social}

En el análisis de las desigualdades sociales, y su correlato con la residencia de los habitantes, indagar sobre la elección territorial adquiere fundamental importancia en virtud de que para las clases desfavorecida y media, frecuentemente, no opera un elemento de intencionalidad en la selección de la ciudad sino, más bien, la aprehensión de las escasas posibilidades de acceso a la vivienda. En ese sentido, mientras que la mayoría de los pobladores de clase desfavorecida consideran que
Cuadro 1: Marco metodológico. Fuente: Elaboración propia a efectos de la investigación. 
son forzados a vivir en territorios informales, los de clase media y alta pueden optar por áreas urbanas formales, es decir, por la adquisición o renta de un inmueble jurídicamente regulado. Expresión de esta residencia forzosa en espacios informales la otorga un jefe de hogar residente en la ciudad de Luque:

Yo no quería venir a un asentamiento por la mala fama que tienen. Yo ya tenía dos hijas, y estaba todo el día fuera de la casa, y mi señora sola en un asentamiento con mis hijas, me iba a preocupar bastante y no quería saber nada de un asentamiento, pero tampoco me alcanzaba la parte económica como para alquilar o adquirir un terreno (J.I., Luque, 2 de julio de 2017).

Los habitantes de clase media del AMA, que ensayan dinámicas vinculadas a la migración interurbana, señalan una conjunción de elementos analizados al momento de escoger un lugar de instalación, destacando que la herencia de propiedades, por parte de familiares, suele ser un elemento de atracción para el asentamiento en ciertos territorios. Para esta clase social, el abanico de opciones para la búsqueda de residencia se encuentra delimitado por cuatro elementos fundamentales: asequibilidad económica, cercanía con grupo familiar (debido a la red de cuidados), accesibilidad y seguridad en torno al barrio. Un habitante de San Lorenzo menciona que para definir su lugar de residencia, tuvo que sopesar la proximidad con la red de cuidados familiares y la disponibilidad económica para adquirir la vivienda:

Nosotros estábamos acostumbrados a que estábamos a una cuadra de la casa de mis papás, mi esposa y yo trabajábamos y nuestro hijo se iba a lo de mamá. Cuando nos mudamos ya no le teníamos a mis padres cerca, y más el trabajo y los traslados..., entonces buscamos una casa a buen precio y cerca de la casa de mis suegros y mi cuñado (J.A., San Lorenzo, 5 de julio de 2017).

En contraste, para la clase alta las posibilidades al escoger su lugar de residencia son menos restrictivas, puesto que no buscan garantizar la cercanía con su grupo familiar exclusivamente por cuestiones de cuidados sino, más bien, por el disfrute de vínculos, coyuntura que, con otras evaluaciones y sumado al poder adquisitivo de las mismas, resulta más favorable para la selección de la ubicación residencial. Para este sector social la seguridad es un elemento primordial, la cual se traduce, principalmente, en la opción de habitar en áreas residenciales cerradas que se encuentran dotadas de dispositivos de control, como cámaras de seguridad y vigilancia constante, siendo también característica de estos emprendimientos la restricción del ingreso de personas extrañas al condominio. Al respecto, al indagar a un residente de San Lorenzo sobre los elementos considerados para la elección de domicilio, el mismo manifestó que:

Yo por razón de mi trabajo paso entre 4 y 5 días, una semana laboral, por el interior del país. Entonces por una cuestión de seguridad me gustaba la idea de que mi señora quedase en un barrio cerrado de forma que, por lo menos, la seguridad no sea una preocupación para mí (R. F., San Lorenzo, 3 de agosto de 2017).

Adicionalmente, estos desarrollos inmobiliarios se encuentran equipados de infraestructura atractiva para que las familias de clase alta 
puedan desenvolverse en un perímetro relativamente pequeño y exclusivo. Respecto a estos barrios cerrados, se debe señalar que, si bien existen diferenciaciones entre los emprendimientos, en los mismos prevalece la particularidad de constituirse como una suburbanización que irrumpe el entorno, con sus características particulares, y desprende a los residentes internos del restante tejido social, puesto que las peculiaridades físicas de estos proyectos operan como símbolos de estatus y distinción socioeconómica, profundizando así los "enclasamientos sociales y la jerarquización territorial" (Ortiz et al., 2017, pp. 105-140). Manifestación de esta elección residencial la expresa un habitante de Lambaré:

Siempre la cercanía es importante, es uno de los factores primordiales y aparte es un barrio cerrado donde tenés seguridad y cierta infraestructura. Ya pensando en el futuro cuando tengamos hijos, tenés la infraestructura para que ellos hagan deportes y hay también colegios cerca (O. A., Lambaré, 18 de julio de 2017).

Asimismo, en el análisis de las desigualdades resulta imperante examinar la incidencia que posee la estructuración urbana desigual sobre la asequibilidad y accesibilidad a servicios básicos de calidad por parte de los residentes urbanos. En este sentido, aunque los indicadores cuantitativos de cobertura de servicios básicos revelan una mejoría para el año 2012 respecto al año 2002, se puede verificar que prevalecen acentuadas asimetrías en el suministro de los mismos.

La provisión de energía eléctrica es el servicio que mayor cobertura alcanza para las viviendas del AMA (ver Cuadro 2). Por su parte, respecto al abastecimiento de agua corriente, si bien tuvo un aumento promedio de 12,6 puntos porcentuales, la ciudad de Luque continúa siendo la más afectada en vista de que el 12,2\% de las viviendas en este territorio aún carecen de dicho servicio. Asimismo, el servicio de recolección de residuos sólidos, que abarca en promedio al $78 \%$ de las viviendas del AMA, cubre las necesidades de menos del $60 \%$ de las viviendas de Luque y Mariano Roque Alonso.

La situación más crítica y las brechas más agudas se visibilizan en la disposición de desagüe cloacal en el AMA: mientras que para el año 2012 Asunción contaba con una cobertura de casi el 70\% de las viviendas con este servicio, las demás ciudades, en promedio, alcanzaban una cobertura de tan solo el 10,5\% de las mismas. Esta deficiencia acarrea, además, un severo daño medioambiental puesto que la insuficiencia en el tratamiento adecuado de las aguas servidas terminan siendo descargadas, principalmente, en arroyos o en el río Paraguay. 


\begin{tabular}{|c|c|c|c|c|c|c|c|c|c|c|c|c|}
\hline \multirow[b]{3}{*}{ Área } & \multicolumn{12}{|c|}{ Años } \\
\hline & \multicolumn{6}{|c|}{2002} & \multicolumn{6}{|c|}{2012} \\
\hline & $\begin{array}{l}\text { Nr. de } \\
\text { vivien- } \\
\text { das }\end{array}$ & $\begin{array}{c}\% \\
\text { Vivien- } \\
\text { das con } \\
\text { energía } \\
\text { eléctri- } \\
\text { ca }\end{array}$ & $\begin{array}{c}\% \\
\text { Vivien- } \\
\text { das con } \\
\text { agua } \\
\text { co- } \\
\text { rrien- } \\
\text { te }\left(^{*}\right)\end{array}$ & $\begin{array}{c}\% \\
\text { Vivien- } \\
\text { das con } \\
\text { des- } \\
\text { agüe } \\
\text { cloacal }\end{array}$ & $\begin{array}{c}\% \\
\text { Vivien- } \\
\text { das con } \\
\text { reco- } \\
\text { lección } \\
\text { de ba- } \\
\text { sura }\end{array}$ & $\begin{array}{c}\% \\
\text { Vivien- } \\
\text { das con } \\
\text { sanea- } \\
\text { miento } \\
\text { mejora- } \\
\text { do }(* *)\end{array}$ & $\begin{array}{c}\text { Nr. de } \\
\text { vivien- } \\
\text { das }\end{array}$ & $\begin{array}{c}\% \\
\text { Vivien- } \\
\text { das con } \\
\text { energía } \\
\text { eléctri- } \\
\text { ca }\end{array}$ & $\begin{array}{c}\% \\
\text { Vivien- } \\
\text { das con } \\
\text { agua } \\
\text { co- } \\
\text { rrien- } \\
\text { te }\left(^{*}\right)\end{array}$ & $\begin{array}{c}\% \\
\text { Vivien- } \\
\text { das con } \\
\text { des- } \\
\text { agüe } \\
\text { cloacal }\end{array}$ & $\begin{array}{c}\% \\
\text { Vivien- } \\
\text { das con } \\
\text { reco- } \\
\text { lección } \\
\text { de ba- } \\
\text { sura } \\
(* * *)\end{array}$ & $\begin{array}{c}\% \\
\text { Vivien- } \\
\text { das con } \\
\text { sanea- } \\
\text { miento } \\
\text { mejora- } \\
\text { do }(* *)\end{array}$ \\
\hline Asunción & 114954 & 99,5 & 88,9 & NR & 88,0 & 94,7 & 96582 & 99,9 & 98,2 & 69,8 & 87,0 & 95,7 \\
\hline $\begin{array}{l}\text { Fernando de } \\
\text { da Mora }\end{array}$ & 25445 & 99,2 & 87,1 & NR & 94,5 & 98,2 & 21779 & 99,9 & 92,7 & 6,9 & 97,3 & 99,7 \\
\hline Lambaré & 25391 & 98,8 & 90,1 & NR & 88,7 & 97,2 & 23625 & 99,8 & 96,3 & 9,6 & 92,4 & 98,8 \\
\hline Luque & 39086 & 97,7 & 64,2 & NR & 55,9 & 92,6 & 42025 & 99,6 & 87,8 & 10,3 & 57,5 & 96,0 \\
\hline $\begin{array}{l}\text { Mariano Ro- } \\
\text { que Alonso }\end{array}$ & 13991 & 98,3 & 77,6 & NR & 48,3 & 92,8 & 15900 & 99,7 & 94,0 & 15,8 & 59,5 & 96,1 \\
\hline San Lorenzo & 44588 & 98,9 & 76,0 & NR & 65,0 & 96,1 & 44637 & 99,8 & 90,2 & 9,8 & 74,5 & 98,9 \\
\hline
\end{tabular}

(*) Incluye: ESSAP, SENASA, red comunitaria y red privada.

(**) Incluye: Desagüe por red pública, pozo ciego con y sin cámara séptica.

(***) Incluye: Recoge camión o camioncito.

Las mejoras en los indicadores de cobertura de servicios básicos no reflejan en sí la calidad en la provisión de los mismos y de los riesgos relacionados con la precariedad de las instalaciones, principalmente las concernientes a agua y energía eléctrica, motivo por el cual la población configura evaluaciones subjetivas negativas al respecto. En cuanto a esto, las clases media y alta de la ciudad de Asunción, pese a ser las que mejor referencias otorgan respecto a la disposición y cobertura de los servicios básicos, manifiestan que el suministro de algunas prestaciones es intermitente. Asimismo, las precariedades comienzan a ser más notorias conforme se expande el territorio urbano, y aún más acentuadas para las clases subalternas. Una jefa de hogar de clase media, residente en San Lorenzo, indica que:

Cuesta muchísimo el tema del agua, cosa que anteriormente no teníamos. Lo que yo veo es que, como los terrenos ya fueron ocupados, se hacen súper mansiones y ahí todos tienen pileta y tenemos una sola aguatería ${ }^{3}$ que nos distribuye a toda la zona. Nosotros tenemos un reservorio de agua con motor pero el agua es tan fea que el olor no te permite ni bañarte, entonces lo que hicimos es que para todo lo que sea la parte de la ropa, conectamos con eso y en lo de mi suegra yo me voy a bañar los fines de semana (M. P., San Lorenzo, 8 de agosto de 2017).

En cuanto a los habitantes de los asentamientos precarios, el acceso a los servicios públicos implica la apelación a la organización comunitaria ya sea para el reclamo ante las autoridades correspondientes o para que desde la gestión mancomunada se viabilice la "auto provisión” de infraestructura y equipamientos que respondan a las necesidades. En consecuencia, las prácticas espaciales, como son la participación, la convivencia cercana, la ayuda mutua, son elementos fundamentales que permiten la construcción del territorio y de las redes sociales, tal como lo expresa una pobladora de la ciudad de Mariano Roque Alonso: nado territorio (generalmente donde no cuentan con abastecimiento de la empresa estatal de Servicios Sanitarios del Paraguay-ESSAP). 
Acá había casas de madera, en el fondo eran carpas liadas por palos. Entonces empecé a hablar con la gente, empecé a ver cómo se podía organizar y formamos una comisión vecinal donde ellos me eligieron como presidenta de comisión. Así metimos luz, metimos agua, calle y otros servicios acá [...] como todo pobre, nos ayudamos entre todos (C. C., Mariano Roque Alonso, 5 de julio de 2017).

La mercantilización de servicios como la salud y la educación han estratificado el acceso con calidad a estas prestaciones: quienes poseen capacidad adquisitiva pueden optar por cubrir estas necesidades provistas por empresas privadas, mientras que aquellos que tienen una economía de subsistencia continúan excluidos y postergados ante estos requerimientos. Respecto a esto, se retoma la denuncia de una habitante capitalina residente en un asentamiento precario:

Nosotros acá no tenemos colegio. Tenemos una sola escuela que está súper poblada y ya nos tenemos que salir para afuera. Hospitales tampoco tenemos. No accedemos a la salud gratuita total, accedemos a un $10 \%$ o $20 \%$, porque los medicamentos que deberían tener, ${ }^{4}$ no tienen. Si vas porque se te rompió la cabeza, no tienen para suturar, tenés que comprar hilo, anestesia, todo (M.D., Asunción, 1 de julio de 2017).

$\mathrm{Al}$ respecto del análisis de las desigualdades sociales y las opciones residenciales que encuentran los habitantes, conviene señalar que los asentamientos urbanos en condición de precariedad son sistemas de organización y producción socio-espacial que desafían los paradigmas hegemónicos de mercantilización del territorio y de la vida urbana, ubicando a la sociedad y el Estado en una constante tensión por la interpretación de cómo se construyen las ciudades. Estos territorios rezagados de la ciudad se erigen al margen de los procesos de formalidad institucional, por tanto son considerados como asentamientos ilegales.

La precariedad constructiva con la cual establecen sus comunidades se cristaliza en los sentimientos de continua inseguridad de que adolecen los habitantes frente a variables climatológicas. La desidia y el desamparo de las instituciones públicas para atender las carencias de estas poblaciones, tanto en materia de infraestructura como en accesibilidad a condiciones de educación, salud y empleo, se encuentran agravados por la inseguridad jurídica en la tenencia de los terrenos y la vivienda, entramado que genera incertidumbre y reiterado reacomodamiento.

Además, esta matriz de privaciones, precariedades, tensiones, disputas y atropello sistemático a los derechos, se remarca ante las experiencias de estigmatización y discriminación que padecen estas comunidades y que confluyen en agudizar las distancias socioeconómicas y colocar aún más lejanas las posibilidades de integración con el tejido urbano. El estigma y la discriminación que perciben estos sectores sociales no tiene un único flanco, los mismos se proyectan en heterogéneas peyorativas hacia sus territorios, sus labores económicas, sus modos de vida y hacia las mismas personas, tal como lo sugiere un poblador de un asentamiento: "nos dicen que somos bañadenses ${ }^{5}$ y que somos bandidos, hasta inclusive algunas veces te piden una referencia personal para el trabajo, y cuando saben de qué barrio venís ya te niegan, te niegan el trabajo" (P. C., Asunción,10 de julio de 2017).

Los residentes de estos asentamientos consideran que existen varios motivos por los cuales la sociedad posee una tendencia a discriminarlos, siendo el principal de ellos el desconocimiento de las realidades
4 En referencia a las Unidades de Salud Familiar y Centros de Salud ubicados en la zona.

5 Gentilicio empleado para denominar a las personas que residen en los Bañados, zonas bajas inundables de Asunción. El término también se ha convertido un adjetivo descalificativo de los pobladores de la zona. 
cotidianas de las familias que residen en estos territorios y de las estructuras económicas que operan para que ellos tengan peores condiciones y menores oportunidades para desarrollarse dentro de la ciudad formal.

En correspondencia, en los discursos aprehendidos de los habitantes de clases media y alta consultados para este trabajo, prevalece un alegato en el cual los menos escépticos identifican con claridad ciertas carencias y secuencia de privaciones de oportunidades que deben atravesar los residentes de los territorios informales. No obstante, la mayoría evalúa que, producto de la restricción de oportunidades, principalmente en educación formal, las familias de estos asentamientos carecen de valores que los motiven a progresar y abandonar la situación de precariedad en la que habitan, dando por sentado que las mismas se encuentran sumisas a un letal conformismo y oportunismo circunstancial que les otorga la residencia en las urbes. La apelación al constreñimiento mental, que les impide proyectar otra vida, es un recurso utilizado para identificar la causa de la invariabilidad de la pobreza urbana, como se manifiesta en el siguiente extracto de entrevista:

La pobreza es una consecuencia de una serie de cosas que se hicieron mal pero tiene un gran componente mental. El pobre cree que va a ser pobre toda su vida, es muy difícil que, de alguna manera, digan "no, yo ¿por qué voy a ser pobre? Yo me voy a abrir camino, voy a comenzar estudiando en una escuela pública, voy a ver la forma de ir a trabajar o, de alguna manera, salir de la calle limpiando vidrios para ir a buscar trabajo y comenzar ganando el salario mínimo para ir creciendo", hay maneras [...] (A.R., Asunción, 26 de julio de 2017).

En virtud de lo expuesto se sostiene que en las ciudades se desarrollan relaciones de poder que reestructuran y revalorizan los territorios. Los grupos de poder económico presionan, directa o indirectamente, a los sectores de bajo poder adquisitivo para expulsarlos de los territorios considerados potencialidades de renta en tanto evalúan que estos grupos actúan como una obstrucción a los procesos de revalorización territorial (Janoschka, 2016). Por tanto, y tal como afirma el autor, "el desplazamiento no es simplemente la salida involuntaria de población que puede ser contabilizada por métodos estadísticos (desplazamiento directo). Expresa una problemática mayor, la injusticia social y espacial que lastra a ciertos grupos en su derecho legítimo a la ciudad, y especialmente en su derecho a usufructo de la centralidad" (ob. cit., 2016, pp. 35-36).

De este modo, se constata el desenvolvimiento no planificado por los habitantes de un espacio urbano socialmente enmarcado por las clases sociales, las cuales estructuran el territorio y habilitan (o restringen) oportunidades ante las cuales los agentes ensayan diferentes estrategias y alternativas de inserción. Para los adultos que residen en asentamientos precarios se percibe una lógica de resiliencia ante el acecho del menosprecio urbano. Su identidad y cohesión comunitaria, así como la reflexión constante en torno a la residencia en la ciudad, se convierten en una impronta de lucha y resistencia que refuerza el convencimiento de estar habilitados a insertarse en cualquier espacio urbano.

En contraste, en las clases media y alta no se reconoce un sistema organizativo comunitario consistente y permanente, probablemente porque las mismas no necesitan viabilizar mecanismos de dotación de infraestructura y equipamientos de los territorios a los que acceden. Por 
tanto, en estos estratos prevalece una apatía por el encuentro colectivo barrial y una casi generalizada indiferencia por el relacionamiento interpersonal con los vecinos.

Además, entre ciudadanos residentes en áreas colindantes a Asunción se identifica una cierta heterogeneidad de clases en sus espacios pero con clara tendencia hacia el aburguesamiento urbano que propicia la homogeneización del paisaje del barrio y la despersonalización en la convivencia.

En consecuencia, en el análisis de la posibilidad de dirimir las barreras simbólicas y materiales entre clases sociales, en pos de generar una mayor cohesión y desarrollo social, los habitantes de los diferentes estratos sociales reflexionan con incredulidad acerca de la construcción genuina de un nuevo modelo de residencia y convivencia urbana. $\mathrm{Al}$ respecto, uno de los elementos más utilizados por las clases media y alta para manifestar tal escepticismo es la oposición de los modos de vida con la clase baja, toda vez que atribuyen que los parámetros propios son los pertinentes mientras que la otredad se presenta como una vida antitética.

Asimismo, la población residente en asentamientos informales considera improbable la residencia conjunta con otras clases sociales al asumir que no serían aceptados como pares sino como sujetos aversivos. Para estas familias el desplazamiento urbano y la posibilidad del encuentro con otras realidades construye el imaginario de que otra forma de residencia es posible, no obstante reparan que la misma debería ser coherente con los lazos afectivos construidos en sus comunidades y no con la apatía que perciben en los espacios modernizados.

\section{El acceso a la vivienda y el hábitat: la contienda social}

La vivienda representa el producto socio-histórico de la construcción simbólica y material realizada por los seres humanos con la finalidad de contar con un espacio que opere como lugar de resguardo y como escenario para la reproducción de la vida. Pese a que la finalidad fundamental de la misma se encuadra en su valor de uso, el mundo contemporáneo ha impuesto una lógica mercantilista sobre este bien, suscitando que en la actualidad el acceso a la vivienda se encuentre mediado por la capacidad económica de los sujetos que deseen disponer de la misma. En dicho sentido, se puede inferir que el acceso a la vivienda, con la consecuente calidad en cuanto a condiciones de materialidad y entorno de instalación, presenta restricciones para los habitantes con condiciones económicas limitadas, configurando experiencias subjetivas dispares con aquellos actores que pueden satisfacer su residencia en condiciones óptimas.

En las reflexiones de los habitantes del AMA se destaca la valoración de la vivienda asociada al atributo de la propiedad privada, como un factor de estabilidad familiar y de seguridad ante la imprevisibilidad.

Para la clase económica desfavorecida, la vivienda de calidad se presenta como un objetivo de alcance remoto a sus posibilidades, de hecho, es recurrente la vinculación con los sueños o los anhelos familiares respecto a este bien que, una vez alcanzados, dignificarán y estabilizarán la vida de estas personas. Las experiencias cotidianas convergen en proyectar que el acceso a una vivienda de calidad implicaría condiciones de materialidad adecuada que les evite la zozobra en caso de inclemencias climáticas, como así también disponer de dependencias que les permitan tener un poco de privacidad entre sus miembros, tal como 
lo expresa una jefa de hogar al ser consultada sobre las significaciones en torno a este bien:

Lo que yo más deseo en la vida es tener una casita de material para poder estar con mis hijos pero hasta hoy en día no tenemos nada y tampoco puedo comprar los materiales. Yo, como toda mamá, sueño que cada uno de mis hijos tenga su pieza, que tengan una cocina, un comedor en donde sentarse a comer en familia (S. O., Lambaré, 11 de julio de 2017).

Pese a considerar que el acceso a la vivienda requiere un esfuerzo en demasía, una lucha constante que ellos mismos llevan por años, la mayoría manifiesta la persistencia de la precariedad en las condiciones de vida por estar confinados a una economía de subsistencia en la cual prima la necesidad de la satisfacción alimentaria, a la cual destinan la mayor parte de sus escasos ingresos.

Por su parte, las clases media y alta acogen similares representaciones respecto a la vivienda puesto que el acceso a la propiedad es considerado como un elemento de seguridad aunque, a diferencia de las clases económicas desfavorecidas, el énfasis no se encuentra puesto sobre la evaluación de la protección contra variables climáticas sino, más bien, sobre la inseguridad ante la alteración de la situación económica familiar o de los términos contractuales de un inquilinato, como lo representa la siguiente afirmación de una pobladora:

Representa seguridad el techo propio. Esa seguridad se traduce en que, aun yo no teniendo que comer, yo tengo un techo donde guarecerme, donde el dueño, si es que fuera alquilada, no va a venir a pedirme la casa, o sea, ese miedo constante de vivir bajo el puente no existe cuando uno tiene su casa (E. B., Fernando de la Mora, 14 de julio de 2017).

Para estas clases, el acceso a la vivienda también representa la posibilidad de obtener mayor privacidad e intimidad pero, en este caso, no se enfatiza desde el hacinamiento que se experimenta intrafamiliarmente sino de las restricciones que se evidencian en la residencia compartida con otros parientes que, pese a operar como mecanismos de cooperación y ayuda, restringe las posibilidades de fortalecer el grupo familiar.

La experiencia cotidiana y la circunstancia socioeconómica son factores que inciden en las construcciones sociales en relación con los indicadores de calidad de la residencia. $\mathrm{Al}$ respecto, las clases desfavorecidas consideran que una vivienda de calidad debe contar con marcaciones entre las diferentes dependencias sin que eso implique taxativamente un dormitorio diferenciado entre padres e hijos o bien por sexo de los hijos. Por el contrario, las clases media y alta realizan mayor énfasis en esta diferenciación espacial y en la necesidad de adaptabilidad de la vivienda según la trayectoria familiar. Ejemplo de dicha divergencia en las representaciones de la calidad habitacional se encuentra en la exposición de dos residentes, el primero de clase baja y el segundo de clase alta, al ser consultados sobre qué consideran que debe tener una vivienda para que sea un espacio familiar habitable:

Para mí, por ejemplo, aunque sea que sea una pieza grande, que tenga techo, alrededor de material, todo un baño, eso es lo más importante... y que tenga agua también (M. T., San Lorenzo, 28 de julio de 2017).

Funcionalmente, la casa debe contar con dormitorios, no para cada hijo, pero si tenés varón y mujer debería ser uno para cada uno, entonces, 
eso te lleva a una casa mínima de dos dormitorios. Los hijos al comienzo, chiquitos, pueden compartir pero después van creciendo y ahí es donde viene la ampliación de la casa (J.E., Asunción, 6 de julio de 2017).

Desde otra perspectiva, es la clase media la que acentúa la relevancia de disponer de accesibilidad para el desarrollo de la vida cotidiana, dando cuenta de que la calidad habitacional no se rige únicamente por parámetros arquitectónicos o de provisión de servicio sino que, necesariamente, involucra la conectividad con equipamientos de salud, educación, trabajo y otros.

En Paraguay, el acceso a la vivienda se puede viabilizar a partir de tres alternativas principales: la compra o alquiler en el mercado privado, el acceso por vía del Estado o bien por la autoproducción y gestión de la vivienda, siendo estas dos últimas categorías las que impactan mayormente a las clases económicas subalternas.

El acceso a la vivienda urbana por parte de las clases económicas desfavorecidas se relaciona con las crecientes dificultades que encuentran para acceder a suelo y vivienda a través del mercado formal. Por tanto, estos sectores se caracterizan por objetivar las respuestas a sus demandas a partir del emprendimiento de acciones discrepantes a las reglamentaciones jurídicas, situación que ubica a sus residencias en las categorías de irregularidad e informalidad, tanto del terreno como de la propia vivienda. La informalidad con la que realizan transacciones económicas o apropiación de terrenos suele provocarles zozobra puesto que no encuentran mecanismos jurídicos que garanticen la tenencia, por tanto frecuentemente se ven obligados a disputar los espacios autoconstruidos por ellos y de los cuales consideran tener habilitadas las garantías de legitima propiedad. En relación con esto, una pobladora relata su experiencia:

Salí yo de ahí ${ }^{6}$ porque tuve un problemita porque compré un lugar, pero después mi pariente me creó problemas. Nosotros compramos el lugar y ahí hice yo toda una casa, mucho gasté, y después de terminarla él dijo que no vendió en realidad ese lugar, y entonces decidí irme nomás de ahí [...] busqué por muchísimos lugares y después encontramos este lugar y compramos por 3000000 , pero gastamos otra vez $10000000^{7}$ por ahí porque los materiales están caros (R. B., Asunción, 11 de julio de 2017).

Las familias instaladas en asentamientos manifiestan que la llegada a los mismos implica una residencia de suma precariedad, con viviendas improvisadas de materiales como plásticos y hules y, a su vez, compromete una gran cuota de esfuerzo para adecuar las condiciones físicas de los lugares a partir de la limpieza y las fragmentaciones territoriales. Luego, progresivamente, las viviendas tienden a ser mejoradas acorde a las posibilidades económicas o los materiales recolectados, como comenta una mujer respecto a su vivencia de instalación en el asentamiento:

Compramos madera terciada y, después, como se derritió toda, mi suegra me dio una casita que ella tiene en el fondo. Después conseguimos para hacer la pieza, de chapa eternit. ${ }^{8}$ Y este, ${ }^{9}$ por ejemplo, nosotros reciclamos, juntamos cosas y empezamos a hacer (M.T., San Lorenzo, 28 de julio de 2017).
6 En alusión a su anterior lugar de residencia.

7 Los montos indicados por la persona entrevistada son en moneda guaraní. El equivalente en euros sería: 3000000 de guaraníes son 420 euros y 10000000 de guaraníes son 1400 euros.

8 Chapa de fibra-cemento.

9 En alusión a una habitación. 
En cuanto al acceso de la vivienda a través de las políticas públicas, se destaca que, en su mayoría, las familias manifiestan incredulidad en cuanto a los procesos de adjudicación toda vez que consideran que son proyectos inaccesibles para personas de escasos recursos o que conllevan excesiva burocracia, como lo describe un jefe de familia:

En el programa de SENAVITAT, ${ }^{10}$ ahora, para acceder a un crédito de vivienda tenés que tener un salario de casi 4 a 5 millones de guaraníes, ${ }^{11}$ es imposible. Es gente totalmente fuera de la realidad social de Paraguay, no hay una política Estado acá de buscar una solución al problema de vivienda, ¿cómo yo como Estado voy a plantear soluciones habitacionales a la población urbana poniendo un salario tan alto? El tema de vivienda acá en el Paraguay no está dirigido a la gente pobre (P.A., Fernando de la Mora, 23 de julio de 2017).

Desde otra perspectiva, un mecanismo de acceso a la vivienda urbana por parte de las clases media o superior, involucra el apoyo que puedan recibir de un familiar cercano. La herencia de propiedades suele ser un elemento impulsor para la vivienda propia o bien la accesibilidad en relación a los alquileres. Para estas familias se encuentra muy presente el acceso a la vivienda formal, aunque algunos tratos de inquilinato o cesiones de derechos de vivienda se den en torno a acuerdos informales, la vivienda, en sí, se encuentra jurídicamente avalada.

Ahora bien, en cuanto se pretende la adquisición o construcción de la vivienda propia, como primeras variables priman la concreción de un crédito y una base, aunque mínima, de ahorro propio. La experiencia respecto a la accesibilidad de los créditos es muy variada pero prevalece la percepción de que en la actualidad existen mayores y más diversificadas ofertas de acceso a la vivienda que en años anteriores, aunque se advierte la permanencia de trámites excesivamente costosos, lentos y engorrosos que implica la postulación a un crédito financiero de improbable adjudicación. Como se puede identificar en el siguiente extracto:

Es muy burocrático. Nosotros tratamos de acceder a entidades públicas y no lo logramos, por más que en ese momento los dos teníamos un buen ingreso salarial. Presentamos todos los requisitos que nos pidieron, todos los papeles, todo completo y no logramos tener una devolución a nuestra solicitud. Al final, llegamos a presentar dos bancos privados. Presentamos los mismos papeles y nunca nos aprobaron, se encajonaron los papeles (J.C., Luque, 19 de julio de 2017).

Para la clase media, el acceso a un crédito conlleva un trayecto de larga búsqueda y consultas, que se traduce en una amalgama de frustraciones por las características de inflexibilidad que presentan las entidades ofertantes, las cuales se relacionan con las condiciones de conformación del grupo familiar y los ingresos salariales de las mismas. Asimismo, la percepción de inaccesibilidad de los créditos, impulsa a las personas a recurrir y agotar mecanismos que deriven en la posibilidad de aprobaciones de los financiamientos que requieren. En este sentido, en algunos habitantes de clases media y alta se encuentra insta-

10 Secretaría Nacional de la Vivienda y el Hábitat. Institución encargada de la política habitacional del país. Actualmente se denomina Ministerio de Vivienda y Urbanismo

11 Equivalente a un salario entre 560 a 700 euros mensuales. lada la convicción de que para acceder a un crédito del mercado, uno debe movilizar una red de contactos dentro de las instituciones. Tal como lo evidencia una jefa de hogar:

Yo no tenía antecedentes de quitar créditos grandes, entonces el tema 
de la amistad es espectacular, teníamos a la contadora que me dijo "yo tengo un conocido que a mí me suele ayudar para el tema de créditos, te voy a dar su número". Le llamé al señor y había sido que él estaba como jefe del área de créditos, entonces me dijo "vas a hacer una nota, dirigido al señor tal, que es el nuevo presidente de la cooperativa, le vas a exponer tu caso". Hice todo y a la tarde me dice que ya estaba mi crédito (M.P., San Lorenzo, 8 de agosto de 2017).

A las restricciones de extensos plazos de financiamiento, elevado monto de las cuotas y de las tasas de interés y la excesiva burocracia, se añade la consideración respecto a la incongruencia existente entre las ofertas de suelo y vivienda en el país en consideración con las genuinas posibilidades de acceder a un financiamiento que cubra tal oferta y que se adecue a la capacidad de endeudamiento de las personas.

En este sentido, un elemento que añade valor al análisis y que permite constatar la experiencia de los ciudadanos respecto a las marcadas inequidades e incongruencias, se presenta con las disparidades en la tenencia de las viviendas según la estratificación de ingresos. Los hogares de Asunción y Central urbano ubicados en los quintiles 4 y 5 acaparan el $67,8 \%$ de las viviendas en condición de propiedad, pago en cuotas o condominio, mientras que la representatividad de los quintiles 1 y 2 para estos indicadores alcanza apenas al 16,9\% (ver Cuadro 3). Similar situación presenta el indicador de viviendas en alquiler, en el cual el 64,4\% de las residencias en esta condición son adquiridas por los quintiles superiores, 4 y 5 , mientras los hogares del quintil 2 no representan ni el 12\% de la condición de inquilinato. Lo expresado permite inferir que los hogares ubicados en los quintiles superiores cuentan con mayores posibilidades de acceso a condiciones de vivienda más seguras que los de los quintiles inferiores que, probablemente, deben rebuscarse entre alternativas que los exponen a menores garantías y mayores informalidades.

\begin{tabular}{|c|c|c|c|c|}
\hline $\begin{array}{l}\text { Asunción y Central } \\
\text { Urbano }\end{array}$ & $\begin{array}{c}\text { Propia, pagando en cuotas } \\
\text { o en condominio }\end{array}$ & $\begin{array}{l}\% \text { Propia, pagan- } \\
\text { do en cuotas o en } \\
\text { condominio }\end{array}$ & Alquilada & $\%$ Alquilada \\
\hline Primer quintil & 23920 & 4,2 & $*$ & $*$ \\
\hline Segundo quintil & 71117 & 12,6 & 395 & 11,8 \\
\hline Tercer quintil & 86281 & 15,3 & 614 & 18,3 \\
\hline Cuarto quintil & 160878 & 28,6 & 783 & 23,4 \\
\hline Quinto quintil & 220989 & 39,2 & 1374 & 41,0 \\
\hline
\end{tabular}

* Número insuficiente de casos para mostrar resultados.

Por último, la satisfacción con la situación residencial revela la acentuada disconformidad de las poblaciones de los asentamientos precarios, puesto que la mayoría de las viviendas no cumplen siquiera con requerimientos mínimos para el desarrollo de vida de los miembros. Las familias que aún no han podido acceder a una vivienda compuesta de materiales perdurables son las que manifiestan la imperante necesidad de poseer espacios adecuados, mientras que aquellas familias que han conseguido construir algunas dependencias con materiales resistibles, alegan necesidades de mejoramiento en la construcción y de ampliación de la vivienda. El residente en una vivienda improvisada, en la capital del país, refiere que:
Cuadro 3: Situación legal de la vivienda según quintiles de ingreso, Asunción y Central Urbano, 2016. Fuente: Elaboración propia a partir de la base de datos de la Encuesta Permanente de Hogares 2016 (DGEEC, 2016b). 
Nosotros tenemos nuestra casa de madera terciada y de chapa "eternit". ${ }^{12}$ Gotea en las tormentas, se mueve todo. En el baño, que no es ni siquiera la mitad de lo que es un baño normal, no tenemos agua caliente, son muchas cosas. Cuando hace frío entra el viento por todos lados (V.L., Asunción, 29 de junio de 2017).

En contraste, las clases media y superior muestran un grado de satisfacción elevado respecto a la calidad habitacional con la que cuentan. No obstante, resaltan que la vivienda no es un constructo estático sino más bien dinámico y progresivo en el cual los proyectos residenciales se van adaptando de acuerdo a las necesidades, a las expectativas y a la capacidad económica de las familias.

\section{Conclusiones}

El territorio urbano metropolitano de Asunción constituye un caso que traduce un proceso histórico-social que no fue objeto de una política pública centrada en atender y compensar las condiciones de precariedad así como tampoco en promover el desarrollo integral de los habitantes. Las dinámicas de configuración urbana, que se presentan como un entramado complejo de estructuración del espacio y las clases sociales, permiten reconocer que hay modos de vida y de relaciones sociales que pugnan en los territorios y entre sus habitantes para instituir los patrones de legitimidad concernientes al carácter propiamente urbano de un territorio.

En dicho sentido, quienes creen poseer los atributos, tanto económicos como de estatus, necesarios para forjar una residencia con calidad en las urbes, emplean alternativas de demarcación socioeconómica y territorial en la cual subyace la pretensión de "sanear" los males asociados con la pobreza. Es entonces que el fenómeno que se reproduce en torno a Asunción y las localidades aledañas se identifica por la coexistencia ( $\sin$ convivir), puesto que, en el variopinto paisaje de las ciudades, se erigen emprendimientos urbanos restringidos, conformados por residentes de un grupo económico bastante homogéneo, el cual cercena la posibilidad de entrada y de relacionamiento con los grupos sociales instalados en áreas colindantes, al mismo tiempo que imponen los nuevos costos que legitimarán la posibilidad de residencia en dichos espacios.

Asimismo, la denominación "los del bajo" y "bañadenses" no son meros atributos topográficos de las ciudades, son categorías descalificadoras que despliegan la asimilación de habitantes subalternos y de espacios degradados. Estas representaciones comulgan con la marcada antítesis espacial urbana: para las clases media y dominante la ciudad posee territorios de necesaria evasión que se legitiman por la estigmatización a la pobreza, en su intento de culpabilizar a los habitantes por su permanente estado de empobrecimiento y actuando como un claro dispositivo de violencia hacia los mismos. Los habitantes y los asentamientos informales son catalogados por los integrantes de otras clases sociales como un sector indeseable con el cual no hay mayor alternativa de coexistencia pero ante el cual se establecen todas las estrategias de segregación y marcas de discriminación.

Finalmente, se puede sostener que este crecimiento de la ciudad, caracterizado por la vertiginosidad y el desentendimiento del Estado en la política de configuración socio-espacial, se halla en la base de la

12 Chapa de fibra-cemento. 
fragmentación y descalificación en los espacios urbanos. Las clases media y superior pueden no constituir los sujetos directos sobre los cuales repercuten las graves condiciones de deterioro físico y ambiental, como es el caso de los habitantes de las zonas socioespacialmente desfavorecidas, sin embargo no están exentos de los efectos de una sociabilidad urbana degradada propia de la lógica neoliberal de colonización de los espacios, dado que se perciben amenazados en su seguridad pública y en sus derechos de propiedad debido a la pobreza y la debilidad del Estado en apuntalar la construcción colectiva del espacio público. 


\section{Referencias bibliográficas}

Antón, Antonio (2013, 7 de diciembre). La desigualdad social. Ponencia (revisada) presentada en las $X$ Jornadas de Pensamiento Crítico. Jornadas organizadas por Acción en Red Recuperado el 10 de setiembre de 2016 de: https:/ /www.uam.es/personal_pdi/ economicas/aanton/publicacion/2014/desigualdad_social.htm\#_ftn1.

Borda, Dionisio (2016). Los elevados costos de las falencias de las políticas públicas. Economía y Sociedad, 44, 9-10. Recuperado el 29 de mayo de 2019 de: http://www.cadep.org.py/2016/11/economia-y-sociedad-n44/.

Bourdieu, Pierre y Wacquant, Loïc (2008). Una invitación a la sociología reflexiva. Buenos Aires: Editorial Siglo XXI (ed. original, 1992).

Castillo, Mercedes (2004). Anotaciones sobre el problema de la vivienda en Colombia. Revista Bitácora Urbano Territorial, 1(8), 15-21. Recuperado el 01 de noviembre del 2017 de: http:/ / www.redalyc.org/articulo.oa? $\mathrm{id}=74800802$.

Causarano, Mabel. (2006). Dinámicas Metropolitanas en Asunción, Ciudad del Este y Encarnación. Paraguay: Fondo de Población de las Naciones Unidas.

Díaz Orueta, Fernando y Lourés Seoane, María Luisa (2013). Neoliberalismo, políticas urbanas y reconfiguración socio-espacial. Quid 16: Revista del Área de Estudios Urbanos, 3, 7-16. Recuperado el 16 de abril de 2019 de: https://dialnet.unirioja.es/servlet/ articulo? codigo $=5593338$.

Dirección General de Estadística, Encuestas y Censos (DGEEG) (2016a). Censos Nacionales 2002-2012. Paraguay: DGEEC.

Dirección General de Estadística, Encuestas y Censos (DGEEG) (2016b). Encuesta Permanente de Hogares 2016. Paraguay: DGEEC. Recuperado el 29 de mayo de 2019 de: https:/ / www.dgeec.gov.py/datos/encuestas/eph.

Durkheim, Émile (2001). Las reglas del método sociológico. México, D. F.: Fondo de Cultura Económica (ed. Original en francés, 1895).

Esquivel Vaesken, Bernardo (2007). Población, desarrollo y lucha contra la pobreza. Población y Desarrollo, 33. Recuperado el 01 de noviembre de 2016 de: http:/ / revistascientificas.una.py/index.php/RE/ article/view/749.

Imas, Víctor (2013). Derecho a la tierra, urbanización y migración. En Dobrée, Patricio (ed.), La tierra en el Paraguay: de la desigualdad al ejercicio de derechos (pp. 179-216). Paraguay: Programa Democratización y Construcción de la Paz.
Janoschka, Michael (2016). Gentrificación, desplazamiento, desposesión: procesos urbanos claves en América Latina. Revista INVI, 31(88), 27-71. Recuperado el 16 de abril de 2019 de: http:/ / www. revistainvi.uchile.cl/index.php/INVI/article/ view/1087.

Morínigo, José (1998). Modernización económica, cultura urbano- industrial y el proceso de urbanización. En Caballero, Javier y Céspedes, Roberto (eds.), Realidad Social del Paraguay. Asunción, Paraguay: Centro Interdisciplinario de Derecho Social y Economía Política.

Moscovici, Serge (1979). El psicoanálisis, su imagen y su público. Buenos Aires: Huemul (ed. Original en francés, 1961).

ONU-Hábitat (2004). Hábitat y desarrollo humano. Bogotá: CENAC/ Un-Hábitat/ PNUD.

Ortiz, Luis (2016). Apuntes para el estudio de las clases en la sociedad paraguaya. En Ortiz, Luis (Ed.), Desigualdad y clases sociales. Estudios sobre la estructura social paraguaya (pp. 239-293). Buenos Aires/Asunción: CEADUC/ICSO/CLACSO.

Ortiz, Luis (ed.), Goetz, Kevin y Gache, Colin (2017). Educación y territorio. Desigualdad y segregación en el área metropolitana de Asunción. Asunción, Paraguay: CEADUC/CADEP.

Prebisch, Raúl (1981). Capitalismo Periférico: crisis y transformación. México, D. F.: Fondo de Cultura Económica.

Rivarola, Milda (2016). Castas y clases. Una lectura de la estructura social paraguaya. En Ortiz, Luis (Ed.), Desigualdad y clases sociales. Estudios sobre la estructura social paraguaya (pp. 61-74). Buenos Aires/Asunción: CEADUC.ICSO.CLACSO

Vázquez, Fabricio (2013). Ciudades intermedias y sustentabilidad urbana en Paraguay. En Dane, Félix (Ed.), El Desafío del Desarrollo Sustentable en América Latina (pp. 223-243). Rio de Janeiro, Brasil: Konrad-Adenauer-Stiftung y SOPLA.

Wirth, Louis (2005). El urbanismo como modo de vida. Bifurcaciones: Revista de estudios culturales urbanos 2, Recuperado el 01 de noviembre del 2017 de: http:/ / www.bifurcaciones.cl/002/bifurcaciones_002_reserva.pdf.

Zavattiero, Georgina (2016). Transformaciones urbanas, segregación social y déficit habitacional: ¿Una relación sincrónica en América Latina y Paraguay? Estudios Paraguayos, 34(2), 117-153. Recuperado el 29 de mayo de 2019 de: http:/ / epy.dreamhosters. com/index.php/RESPY/article/view/41. 
Zavattiero Tornatore, Georgina y Ortiz Sandoval, Luis Alberto (2019). Urbanización y clases sociales. La experiencia de la desigualdad en la estructuración del área metropolitana de Asunción. Hábitat y Sociedad, 12, 91-111.

<http://dx.doi.org/10.12795/HabitatySociedad.2019.i12.06>

$\bigcirc$ 


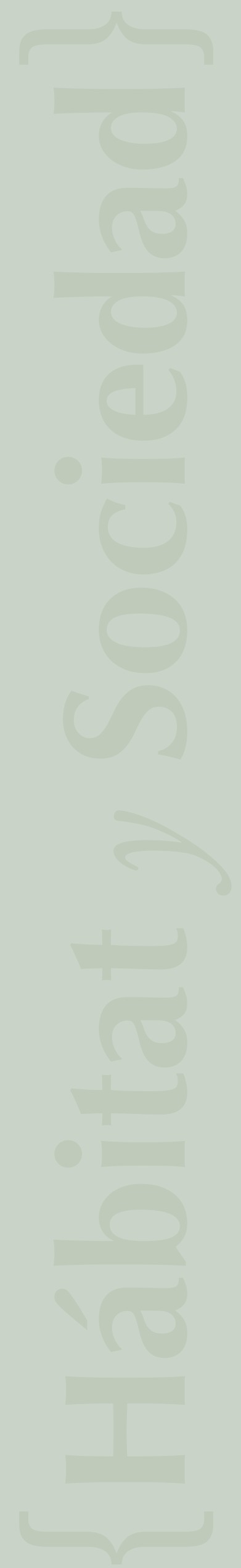

